University of Nebraska - Lincoln

DigitalCommons@University of Nebraska - Lincoln

Publications from USDA-ARS / UNL Faculty

U.S. Department of Agriculture: Agricultural

Research Service, Lincoln, Nebraska

2015

Cold temperature disinfestation of bagged flour

P. W. Flinn

Retired, pwflinn@gmail.com

F. H. Arthur

USDA-ARS, frank.arthur@ars.usda.gov

James E. Throne

USDA-ARS, Manhattan, KS, james.throne@ars.usda.gov

K. S. Friesen

USDA-ARS, ken.friesen@ars.usda.gov

K. L. Hartzer

USDA-ARS

Follow this and additional works at: https://digitalcommons.unl.edu/usdaarsfacpub

Flinn, P. W.; Arthur, F. H.; Throne, James E.; Friesen, K. S.; and Hartzer, K. L., "Cold temperature disinfestation of bagged flour" (2015). Publications from USDA-ARS / UNL Faculty. 2057.

https://digitalcommons.unl.edu/usdaarsfacpub/2057

This Article is brought to you for free and open access by the U.S. Department of Agriculture: Agricultural Research Service, Lincoln, Nebraska at DigitalCommons@University of Nebraska - Lincoln. It has been accepted for inclusion in Publications from USDA-ARS / UNL Faculty by an authorized administrator of DigitalCommons@University of Nebraska - Lincoln. 


\title{
Cold temperature disinfestation of bagged flour
}

\author{
P.W. Flinn", , F.H. Arthur, J.E. Throne ${ }^{2}$, K.S. Friesen, K.L. Hartzer \\ USDA, Agricultural Research Service, Center for Grain and Animal Health Research, 1515 College Avenue, Manhattan, KS 66502, USA
}

\section{A R T I C L E I N F O}

\section{Article history:}

Received 9 February 2015

Received in revised form

10 June 2015

Accepted 12 June 2015

Available online 23 June 2015

\section{Keywords:}

Tribolium castaneum

Freezing mortality

Stored-product insect control

\begin{abstract}
A B S T R A C T
We conducted studies using a commercial freezer maintained at $-17.8^{\circ} \mathrm{C}$ to determine the time needed to kill Tribolium castaneum eggs in a pallet of flour. Each bag weighed $22.7 \mathrm{~kg}$, and there were 5 bags in each of 10 layers. The dimensions of the pallet were $109-\mathrm{cm}$ wide by $132-\mathrm{cm}$ long by $123-\mathrm{cm}$ tall, and the weight of the stacked pallet was approximately $1152 \mathrm{~kg}$. We conducted tests for nine internal goal temperatures of $-12,-10,-8,-6,-4,-2,0,4$ and $8{ }^{\circ} \mathrm{C}$. Internal temperatures in the most central location of the flour pallet reached: $-11.0,-9.4,-6.9,-5.0,-3.5,-1.6,-0.1,3.3$, and $5.6{ }^{\circ} \mathrm{C}$ and were achieved after 11.0, 9.1, 8.9, 7.2, 6.7, 5.8, 5.5, 5.2, and 4.2 days, respectively. For treatments where the goal temperature for the center bag ranged from -12 to $4{ }^{\circ} \mathrm{C}$, egg mortality was $100 \%$ in bags located in both the periphery and in the center of the pallet. When the temperature goal for the center bag was $8{ }^{\circ} \mathrm{C}$, $7 \pm 2.5 \%$ of the eggs survived in bags located near the center of the pallet. Our data showed that temperatures that follow the dynamic temperature curve that takes place over 24.2 days (cool down and warm up for the $0{ }^{\circ} \mathrm{C}$ temperature goal) resulted in $100 \%$ mortality of $T$. castaneum eggs. The reason for the difference in mortality for a static compared to a dynamic temperature treatment may be due to the fact that the dynamic temperature treatment occurs over a much longer duration. The fact that the treatment only required 5.5 days in the freezer before it could be shipped makes it a practical method to disinfest pallets of flour, especially because the bags do not need to be removed from the pallet and no chemicals are used.
\end{abstract}

Published by Elsevier Ltd.

\section{Introduction}

Tribolium castaneum (Herbst), the red flour beetle, and Tribolium confusum Jacqueline duVal, the confused flour beetle, are two major stored-product insect pests of flour mills in the United States (US). Insect pest management strategies for these beetles and other stored-product beetles in general can include the use of contact insecticides as surface treatments, aerosols, and fumigants (Arthur, 2012; Boina and Subramanyam, 2012). Eggs are generally considered to be the life stage most tolerant to fumigants (Bell and Savvidou, 1999) and aerosols (Arthur, 2010) although less data are available for susceptibility to aerosols compared to fumigants.

Since 2005 the fumigant methyl bromide as a structural treatment for mills has been in the process of being phased out in most developed countries, under the terms outlined in the Montreal

\footnotetext{
* Corresponding author.

E-mail address: pwflinn@gmail.com (P.W. Flinn).

1 Retired.

2 Current address: USDA, Agricultural Research Service, San Joaquin Valley Agricultural Sciences Center, 9611 South Riverbend Avenue, Parlier, CA 93648, USA.
}

Protocol (Fields and White, 2002). Whole plant treatments as alternatives to methyl bromide include use of the fumigants sulfuryl fluoride and some cylinderized applications of phosphine (Arthur, 2012). Another alternative to fumigants is the use of heat treatments, and there has been considerable research on using heat as a structural treatment for stored-product insects (Subramanyam et al., 2011).

The use of cool or cold temperatures to manage stored grain can be an important component of insect pest management programs for bulk grains (Navarro et al., 2002, 2012). Development of most insect pests of stored grain is limited at or below $15{ }^{\circ} \mathrm{C}$ (Fields, 1992), and there are strategies for using different temperature thresholds to progressively cool the grain mass (Arthur and Casada, 2010). Bulk grain is an excellent insulator, and the center of the grain mass will take longer to transfer temperatures compared to the peripheral and top regions of the grain (Jian et al., 2009; Jian and Jayas, 2012). Aeration with low-volume ambient air is rarely used to kill insects; instead the goal is to limit insect development by modification of the bulk grain mass (Navarro et al., 2012). Computer models have been developed that predict insect population growth in grain bins using different aeration strategies to 
cool the grain (Flinn et al., 1997).

Using cold temperatures or grain chilling to kill insects is also a potential control option for bulk grains (Rulon et al., 1999; Navarro, 2012), but the use of cold to disinfest palletized bulk bagged commodities has not been extensively researched. Stacked bagged commodities such as flour would be expected to have similar heat transfer processes as what has been observed for bulk grain, i. e., the center region of a stacked pallet would take longer to cool than the peripheral regions. Using cold temperatures to disinfest an entire facility may be potentially possible in colder climates (Worden, 1987), but this strategy would be limited throughout most of the temperate and southern regions of the US for much of the year. A more promising approach would be investigating the use of cold temperatures to disinfest a pallet or several pallets of goods that are suspected of being infested by flour beetles, using a large freezer. Commercial freezers have options for determining a set point, but sources from the milling industry in the USA state that an industry standard is $-17.8^{\circ} \mathrm{C}$. There are no recent studies in the scientific literature investigating cold temperatures as a disinfestation treatment for bulk commodities such as bagged flour. Therefore, the objectives of this study were to determine: 1) cooling patterns in a pallet load of bulk bagged flour, using a set threshold of $-17.8{ }^{\circ} \mathrm{C}, 2$ ) time and temperature required to kill T. castaneum eggs, based on determination of the cooling patterns described in objective 1 , and 3 ) differences in cooling rates of the bulk and peripheral regions, and the resulting effect on egg mortality.

\section{Materials and methods}

Studies were conducted to determine the time needed to kill T. castaneum eggs contained in $5 \mathrm{ml}$ vials inserted into $22.7 \mathrm{~kg}$ bags of flour (approximate dimensions of $61 \times 41 \times 10 \mathrm{~cm}$, enriched bakery flour, Stafford County Flour Mill, KS) at target temperatures of $-12,-10,-8,-6,-4,-2,0,4$ and $8{ }^{\circ} \mathrm{C}$ for the most central location in the pallet. We used the egg stage of T. castaneum in our study because that is the species and life stage of most concern to the milling industry in the USA. Twenty $T$. castaneum eggs that were approximately 1 -day-old were added to a $5 \mathrm{ml}$ conical snap cap vial that contained $3 \mathrm{~g}$ of pre-sieved flour (\#50 sieve with $8-\mathrm{mm}$ openings). The eggs were obtained from a strain collected from a food warehouse in 2005 and had been reared at the USDA-ARS Center for Grain and Animal Health Research (CGAHR) since that time. This strain was reared on a diet of $95 \%$ all-purpose flour and $5 \%$ Brewer's yeast in an incubator set at $27{ }^{\circ} \mathrm{C}$ in total darkness. An 8 -mm hole was made in each vial lid. A small piece of silkscreen was laid across the top of the vial, and it was held in place by the vial top. Four flour bags, (A1, J1, E2, and F2) were selected to have vials containing eggs inserted into them (Fig. 1). We selected these bags because they represented the two most peripheral and central bags in the pallet. We used two monitoring positions in the two most center bags (E2 and F2). In addition to inserting 5 vials into the center of these bags, we also inserted 5 vials and a thermistor into a location that represented the center of the flour mass for the pallet (E2Q and F2Q). A small v-shaped flap was made in the center front of the flour bag to insert the vials into the flour. Five vials were inserted into the center of each bag, a Hobo TMCX-HD thermistor cable (Onset Computers, Bourne, MA, USA) was inserted between the 5 vials, and then the paper flap on the bag was sealed using plastic packaging tape. We assembled the pallet by laying five bags on a $122 \times 102 \mathrm{~cm}$ wooden pallet (Fig. 1). Five additional bags were then added for each layer for a total of 10 layers. The sides of the pallet were then wrapped with plastic film to help hold the bags in place and to protect the bags from damage (this is normally done for commercial shipments). The final dimensions of the pallet were

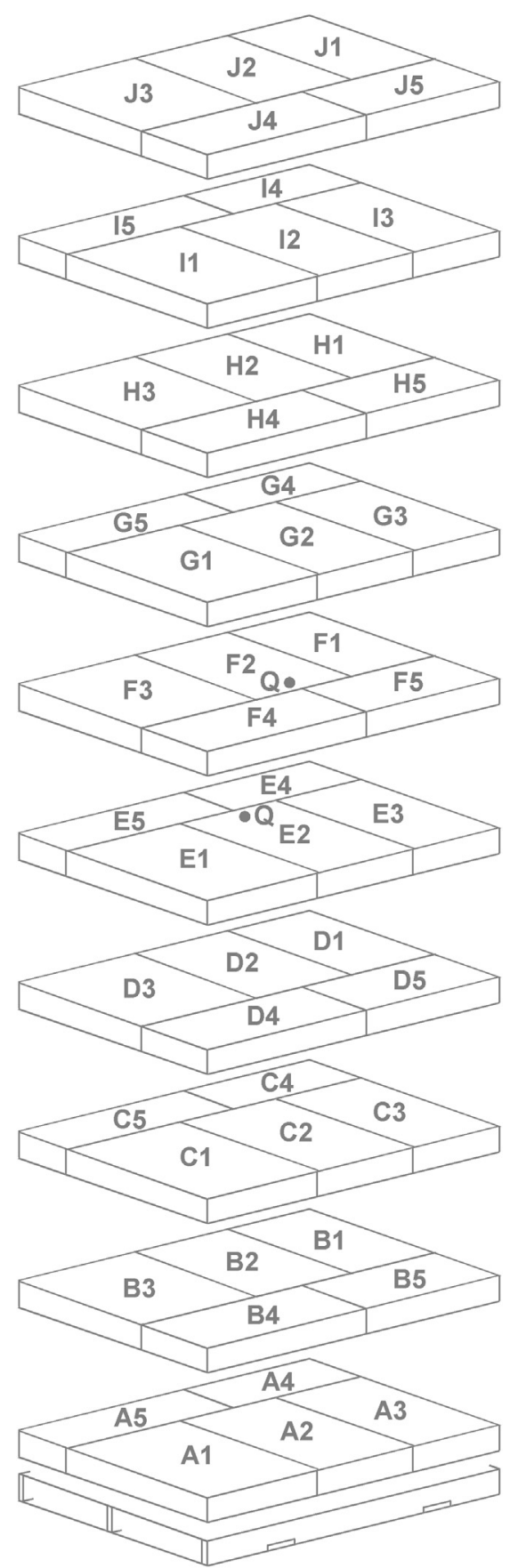

Fig. 1. Arrangement of flour bags on the pallet.

about $1.09 \mathrm{~m}$ wide by $1.32 \mathrm{~m}$ long by $1.23 \mathrm{~m}$ tall. The weight of the stacked pallet was approximately $1152 \mathrm{~kg}$. The thermistor cables from each bag of flour were then connected to U12-006 Hobo data loggers, 4 cables per logger (Onset, Bourne MA). Temperatures were recorded at 10 min intervals. We also monitored real-time temperature in the center bags of the pallet using a Hobo ZW-006 wireless data node and a ZW-RCVR Hobo data receiver (Onset, Bourne, MA, USA). Real-time data were needed to determine when to stop the cold temperature treatments at predetermined temperature thresholds, and to avoid disturbing the treatment.

The pallet was then moved into a $3.1 \times 4.9 \mathrm{~m}$ walk-in freezer (Polar King International, Inc. Fort Wayne, IN) located at CGAHR that was set at $-17.8^{\circ} \mathrm{C}$. Three bags of flour were used as a control, 
which were set inside a chamber (Percival Scientific Inc. Perry, IA) at CGAHR set at $22{ }^{\circ} \mathrm{C}$. The same methods as described above were used to insert 5 vials, each containing 20 eggs of $T$. castaneum, into each bag. This environmental chamber was inside a room within the main building at the CGAHR, which was temperaturecontrolled. The freezer was inside an outer building on the grounds of the CGAHR; the building itself was heated but not air conditioned and thus strict temperature controls were not maintained. After the pallet was removed from the freezer, it was transported to the temperature-controlled room. All studies were conducted from November 2012 through August 2013, and temperatures inside the temperature-controlled room ranged from about 20 to $24{ }^{\circ} \mathrm{C}$. Sample vials were left in the pallet until the internal temperature in locations E2Q and F2Q reached the ambient temperature of the temperature-controlled room; after which the samples were removed from the bags and placed in a chamber maintained at $27.5{ }^{\circ} \mathrm{C}$ for 21 days. This was done so that any surviving eggs would mature and develop into the 4th or 5th instar. After 21 days the flour in the vials was sieved with a U.S. standard \#50 sieve (0.30-mm opening) to separate larvae from the flour. Larvae were classified as alive if movement was observed after touching them with a brush. Vials in the control bags were removed from the bags at the same time that the treatment vials were removed from the bags in the pallet. Control vials were incubated at $27.5{ }^{\circ} \mathrm{C}$ for durations of $6-13$ days. The incubation time for the controls was based on data from Howe (1965) that would result in larvae developing into 4 th or 5 th instar. After the incubation period, the control samples were sieved to separate larvae from the flour.

Data were analyzed using SAS/STAT 8.01 for Windows (SAS Institute, Cary NC) (SAS Institute, 2000) to compare egg survivorship as a function of minimum temperature reached in the most central region of the flour pallet. Data were also plotted and models for temperature $(y)$ as a function of time $(x)$ were determined and fit using Table Curve 2D software (5.01, Systat Inc. San Jose CA).

\section{Results and discussion}

Internal temperatures where the temperature sensor was in the most central location of the flour pallet (F2Q see Fig. 1) were: $-11.0,-9.4,-6.9,-5.0,-3.5,-1.6,-0.1,3.3$, and $5.6{ }^{\circ} \mathrm{C}$ and were achieved after $11.0,9.1,8.9,7.2,6.7,5.8,5.5,5.2$, and 4.2 days, respectively (Table 1 ). After the pallet was placed into the freezer, flour temperatures decreased faster in bags located on the periphery of the pallet (A1 and J1) compared to bags in the center of the pallet (F2, E2). It took about 11.1 days for flour temperature in the center bags to reach the temperature goal of $-12.0^{\circ} \mathrm{C}$ and about 3.3 days for temperatures in the peripheral bags $\mathrm{A} 1$ and $\mathrm{J} 1$ to reach $-12.0{ }^{\circ} \mathrm{C}$ (average of the two positions A1 and J1). Temperatures in the peripheral bags $\mathrm{A} 1$ and $\mathrm{J} 1$ continued to decrease and reached a minimum temperature of $-17.1^{\circ} \mathrm{C}$ after 10.6 days.

The minimum temperature that is reached in the center of the flour pallet is much more important than peripheral temperatures because it is in the center that eggs are much more likely to survive a low temperature treatment because the center stays warmer longer than the periphery. Because the temperature in the center mass position F2Q continued to decrease even after the pallet was removed from the freezer, we had to estimate how much the temperature would continue to decrease following removal from the freezer. In the case of the $-12{ }^{\circ} \mathrm{C}$ goal, the flour temperature in the center mass location $\mathrm{F} 2 \mathrm{Q}$ did not reach $-12^{\circ} \mathrm{C}$ and only reached a minimum of $-11^{\circ} \mathrm{C}$. This did not cause a problem in data analysis because subsequent experiments at temperature goals of $-8,-6,-4,0$, and 4 resulted in $100 \%$ egg mortality. After the pallet was removed from the freezer and transported to the temperature-controlled room at CGAHR, it took 26.8 days for the bags in the center of the flour mass to warm to the ambient conditions in the room. A model was fit to the temperature data in the center of the flour mass (F2Q):

$\mathrm{y}=\left(\mathrm{a}+\mathrm{cx}^{0.5}+\mathrm{ex}+\mathrm{gx}^{1.5}+\mathrm{ix}^{2}\right) /\left(1+\mathrm{bx}^{0.5}+\mathrm{dx}+\mathrm{fx}^{1.5}+\mathrm{hx}^{2}\right)$ $\mathrm{R}^{2}=0.99$, where $\mathrm{y}=$ days, $\mathrm{x}={ }^{\circ} \mathrm{C}, \mathrm{a}=21.2, \mathrm{~b}=-1.26, \mathrm{c}=-27.8$, $\mathrm{d}=0.607, \mathrm{e}=13.7, \mathrm{f}=-0.132, \mathrm{~g}=-3.01, \mathrm{~h}=0.0109, \mathrm{i}=0.248$ (Fig. 2).

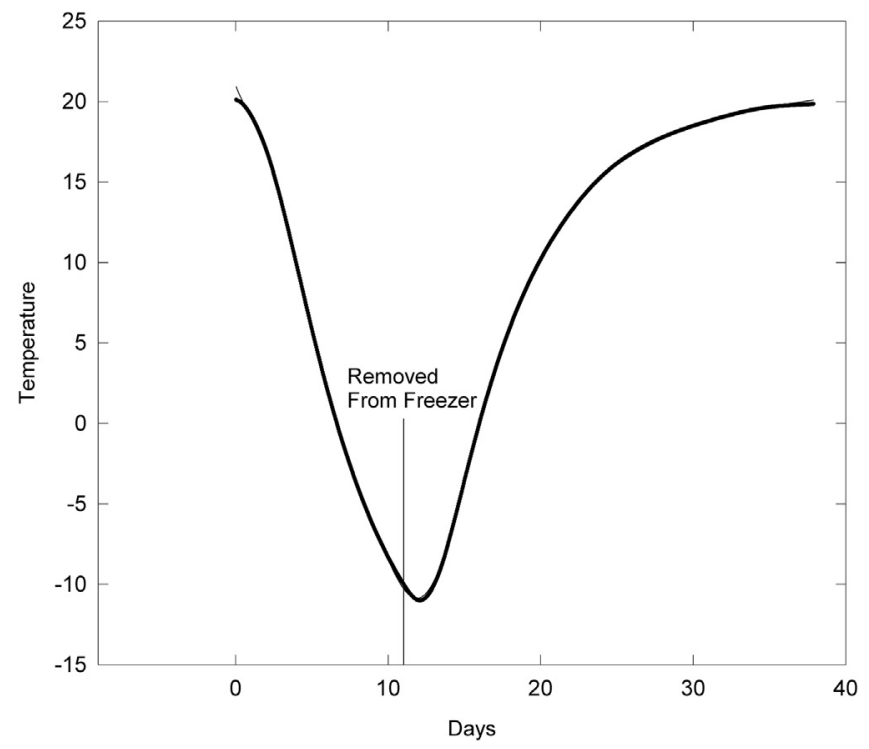

Fig. 2. Temperature data and fitted equation for $-12.0{ }^{\circ} \mathrm{C}$ temperature goal for the center location in the flour pallet (F2Q). Bold line is the actual flour temperature and the thin line is the fitted equation. Before being placed into the freezer the temperature of the flour was $20.2{ }^{\circ} \mathrm{C}$.

Table 1

Effects of minimum temperature at the pallet center and edge on percentage survival for T. castaneum eggs ( \pm standard error).

\begin{tabular}{|c|c|c|c|c|c|c|c|c|}
\hline Minimum temperature goal & Days $^{a}$ & Outer edge top & Outer edge bottom & Center $\mathrm{E} 2^{\mathrm{b}}$ & Center E2Q ${ }^{c}$ & 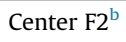 & Center F2Q ${ }^{\mathrm{C}}$ & Control \\
\hline-12 & 11.0 & $0.0 \pm 0.0$ & $0.0 \pm 0.0$ & $0.0 \pm 0.0$ & $0.0 \pm 0.0$ & $0.0 \pm 0.0$ & $0.0 \pm 0.0$ & $52.0 \pm 10.0$ \\
\hline-10 & 9.1 & $0.0 \pm 0.0$ & $0.0 \pm 0.0$ & $0.0 \pm 0.0$ & $0.0 \pm 0.0$ & $0.0 \pm 0.0$ & $0.0 \pm 0.0$ & $64.7 \pm 3.0$ \\
\hline-8 & 8.9 & $0.0 \pm 0.0$ & $0.0 \pm 0.0$ & $0.0 \pm 0.0$ & $0.0 \pm 0.0$ & $0.0 \pm 0.0$ & $0.0 \pm 0.0$ & $73.7 \pm 2.4$ \\
\hline-6 & 7.2 & $0.0 \pm 0.0$ & $0.0 \pm 0.0$ & $0.0 \pm 0.0$ & $0.0 \pm 0.0$ & $0.0 \pm 0.0$ & $0.0 \pm 0.0$ & $45.3 \pm 3.1$ \\
\hline-4 & 6.7 & $0.0 \pm 0.0$ & $0.0 \pm 0.0$ & $0.0 \pm 0.0$ & $0.0 \pm 0.0$ & $0.0 \pm 0.0$ & $0.0 \pm 0.0$ & $32.0 \pm 3.3$ \\
\hline-2 & 5.8 & $0.0 \pm 0.0$ & $0.0 \pm 0.0$ & $0.0 \pm 0.0$ & $0.0 \pm 0.0$ & $0.0 \pm 0.0$ & $0.0 \pm 0.0$ & $45.0 \pm 2.8$ \\
\hline 0 & 5.5 & $0.0 \pm 0.0$ & $0.0 \pm 0.0$ & $0.0 \pm 0.0$ & $0.0 \pm 0.0$ & $0.0 \pm 0.0$ & $0.0 \pm 0.0$ & $68.0 \pm 2.9$ \\
\hline 4 & 5.2 & $0.0 \pm 0.0$ & $0.0 \pm 0.0$ & $0.0 \pm 0.0$ & $0.0 \pm 0.0$ & $0.0 \pm 0.0$ & $0.0 \pm 0.0$ & $83.3 \pm 1.7$ \\
\hline 8 & 4.2 & $0.0 \pm 0.0$ & $0.0 \pm 0.0$ & $7.0 \pm 2.5$ & $7.0 \pm 3.0$ & $2.0 \pm 1.2$ & $0.0 \pm 0.0$ & $82.3 \pm 1.7$ \\
\hline
\end{tabular}

a Days is the number of days the pallet was in the $-17.8^{\circ} \mathrm{C}$ freezer.

b The bag F2 is located in the 5th layer down from the top and is the center-most bag, The bag E2 is located in the 6th layer down from the top and is the center-most bag.

c F2Q is in the pallet center location of bag F2, E2Q is in the pallet center location of bag E2. 
For treatments where the temperature goal for the center bag was $-12,-10,-8,-6,-4,-2,0$, and $4{ }^{\circ} \mathrm{C}$, egg survivorship was $0 \%$ in bags located in the periphery and in the center of the pallet (Table 1). When the temperature goal for the center bag was $8{ }^{\circ} \mathrm{C}$, $7.0 \%$ of the eggs survived in bag E2, $7.0 \%$ in location E2Q $2.0 \%$ survived in bag F2, and none survived in location F2Q. For all of the treatments tested, none of the eggs located in bags in the periphery (A1, J1) survived.

As expected, the number of days to reach the desired temperature in the center bags decreased as the temperature goal increased. For example, for the temperature goals of $-12.0^{\circ} \mathrm{C}$ and $0{ }^{\circ} \mathrm{C}$, the times required to reach these temperatures in the center bags were 11.0 and 5.5 days, respectively (Table 2). For the peripheral bags (A1, J1) it took only 3.3 and 0.9 days, respectively, to reach the temperature goals of $-12.0{ }^{\circ} \mathrm{C}$ and $0{ }^{\circ} \mathrm{C}$. For commercial treatments it is important to minimize the time required to disinfest flour pallets so that the flour can be shipped out as soon as possible. Because egg survivorship was $0 \%$ for both peripheral and central locations at the temperature goal of $0{ }^{\circ} \mathrm{C}$, this should be a good treatment recommendation for flour pallets. The cool down and warm up data for this treatment showed thermal inertia for flour located in the center bag, F2Q (Fig. 3). Even though the pallet was removed from the freezer at 5.5 days, the temperature in the center bag continued to decrease for an additional 2.0 days. The temperature of the center bag was $5.0^{\circ} \mathrm{C}$ when the pallet was removed from the freezer, and reached a minimum temperature of $0.1{ }^{\circ} \mathrm{C} 2.0$ days later. This is a result of a "wave" of cooler temperatures from the periphery slowly moving towards the center of the pallet of flour even after the pallet was removed from the freezer (Table 2). A model was fit to the zero temperature goal treatment: $\mathrm{y}=\left(\mathrm{a}+\mathrm{cx}^{2}+\mathrm{ex}^{4}+\mathrm{gx}^{6}\right) /\left(1+\mathrm{bx}^{2}+\mathrm{dx}^{4}+\mathrm{fx}^{6}+\mathrm{hx}^{8}\right) \mathrm{R}^{2}=0.99$, where $\mathrm{y}=$ days, $\mathrm{x}={ }^{\circ} \mathrm{C}, \mathrm{a}=20.6, \mathrm{~b}=-0.0104, \mathrm{c}=-0.752$, $\mathrm{d}=0.000301, \mathrm{e}=0.00732, \mathrm{f}=-3.78 \mathrm{e}-07, \mathrm{~g}=-7.53 \mathrm{e}-06, \mathrm{~h}=5.61 \mathrm{e}-$ 11 (Fig. 3). This model can be used to predict temperature change for a pallet of flour with similar mass and dimensions to the pallet that was used in our experiments.

Studies using static temperatures showed that temperatures lower than $0{ }^{\circ} \mathrm{C}$ were required to achieve significant mortality of T. castaneum eggs. Mullen and Arbogast (1979) showed that at $-5{ }^{\circ} \mathrm{C} 50 \%$ of $T$. castaneum eggs survived for 0.3 days. Studies with the related species T. confusum showed that 50\% of eggs exposed to $-6{ }^{\circ} \mathrm{C}$ survived for 0.2 days (Nagel and Shepard, 1934). Based on results from our study, these very low temperatures are not required to cause $100 \%$ mortality to . castaneum eggs in flour if the treatment occurs over a longer duration. Our data show that temperatures that follow the dynamic temperature curve that takes place over 24 days (cool down and warm up for the $0{ }^{\circ} \mathrm{C}$ temperature goal) resulted in $100 \%$ mortality for T. castaneum eggs in both

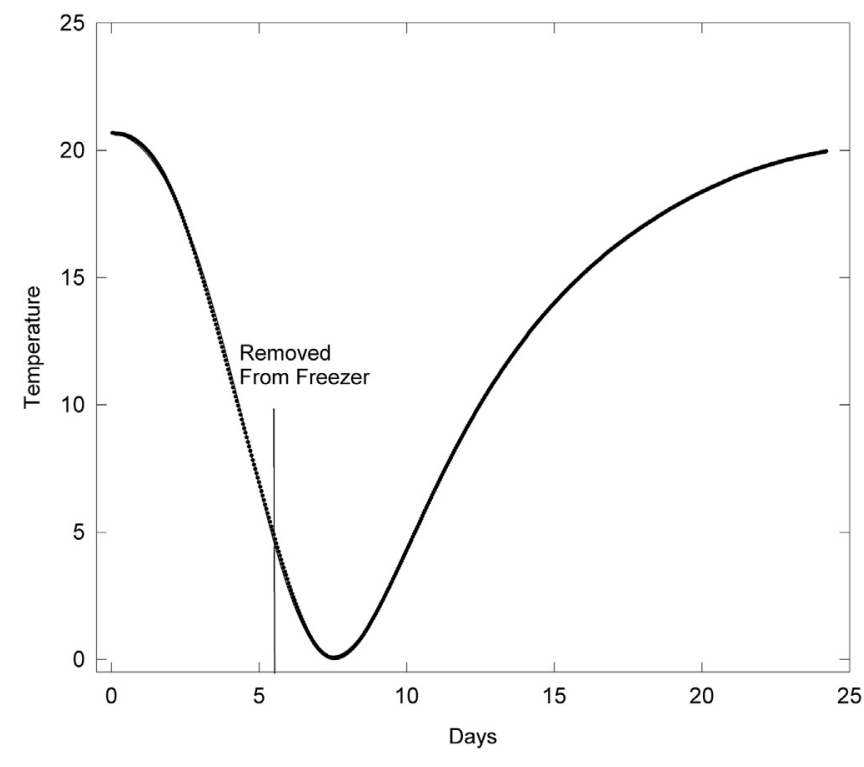

Fig. 3. Temperature data and fitted equation for $0{ }^{\circ} \mathrm{C}$ temperature goal for the center location in the flour pallet (F2O). Bold line is the actual flour temperature and the thin line is the fitted equation (note: the model fits very well so the thin line is covered by the thicker line). Before being placed into the freezer the temperature of the flour was $20.9{ }^{\circ} \mathrm{C}$.

the peripheral and center bag locations. Johnson and Valero (2003) conducted studies in a commercial freezer set at $-18^{\circ} \mathrm{C}$ to examine cooling patterns in bulk stored garbanzo beans in relation to disinfestation of different life stages of the cowpea weevil, Callosobruchus maculatus (F.). Eggs were the most tolerant life stage and adults were the least tolerant life stage. They also examined cooling patterns in the bulk bin where the beans were stored, and similar to our study, also found that cooling rates at the center of the bulk mass were slower compared to the outside regions. The bin used in their study was $2.2 \mathrm{~m}^{3}$, which is slightly larger than the dimensions of the flour pallet of $1.77 \mathrm{~m}^{3}$ used in our study. However, $100 \%$ egg mortality occurred even when the center mass had not reached the target temperatures, which was also similar to the results in our study.

Both our study and Johnson and Valero (2003) showed different results for a dynamic temperature treatment compared to a static temperature treatment. A plausible explanation for the difference in mortality between static versus dynamic treatments may be due to the fact that the dynamic temperature treatment occurs over a much longer duration. For example, in our zero temperature goal treatment, it took 24 days for the temperature in the center bag to

Table 2

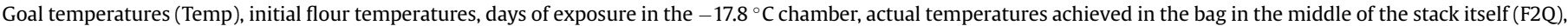

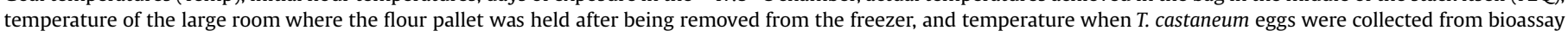
containers.

\begin{tabular}{|c|c|c|c|c|c|c|}
\hline Goal temp ${ }^{\circ} \mathrm{C}$ & Initial flour temp & Days in $-17.8^{\circ} \mathrm{C}$ chamber & Lowest temp center ${ }^{\mathrm{a}}$ & Ambient recovery temp & Days at ambient temp & Temp at collection center bag ${ }^{\mathrm{b}}$ \\
\hline-12 & 20.2 & 11.0 & -11.0 & 20.8 & 26.9 & 20.0 \\
\hline-10 & 20.4 & 9.1 & -9.4 & 20.6 & 28.9 & 19.7 \\
\hline-8 & 20.1 & 8.9 & -6.9 & 20.8 & 27.1 & 20.0 \\
\hline-6 & 20.2 & 7.2 & -5.0 & 20.7 & 26.9 & 19.9 \\
\hline-4 & 20.4 & 6.7 & -3.5 & 20.8 & 26.0 & 20.2 \\
\hline-2 & 20.2 & 5.8 & -1.6 & 21.0 & 23.1 & 20.1 \\
\hline 0 & 20.9 & 5.5 & -0.1 & 21.1 & 18.8 & 20.1 \\
\hline 4 & 25.4 & 5.2 & 3.3 & 23.3 & 12.8 & 20.4 \\
\hline 8 & 23.8 & 4.2 & 5.6 & 23.1 & 9.8 & 18.3 \\
\hline
\end{tabular}

${ }^{\text {a }} \mathrm{F} 2 \mathrm{Q}$ is in the pallet center location of bag F2.

b The bag F2 is located in the 5th layer down from the top and is the center-most bag. 
go from $20^{\circ} \mathrm{C}$ to $0.1{ }^{\circ} \mathrm{C}$ and back up to $20{ }^{\circ} \mathrm{C}$. This relatively long exposure to low temperatures results in $100 \%$ egg mortality. For commercial purposes it would not be necessary to wait for the center of the pallet to warm to ambient before shipping, which means the pallet could be shipped after the 5.5 days of treatment in the freezer.

Our study showed that treating flour pallets in commercial freezers is a feasible method to disinfest flour that may be infested with $T$. castaneum eggs. The fact that the treatment only required 5.5 days in the freezer makes it a practical method to disinfest pallets of flour, especially because the flour does not need to be removed from the shipping pallet. The fact that no chemicals are used would allow use of this treatment for organic or conventional flour.

\section{Acknowledgments}

We wish to give special thanks to Ann Redmon for excellent technical support. This paper reports the results of research only. Mention of trade names or commercial products in this publication is solely for the purpose of providing specific information and does not imply recommendation or endorsement by the U.S. Department of Agriculture. The U.S. Department of Agriculture is an equal opportunity provider and employer.

\section{References}

Arthur, F.H., 2010. Residual efficacy of aerosols to control Tribolium castaneum and Tribolium confusum. In: Carvalho, M.O., et al. (Eds.), Proceedings of the 10th International Working Conference on Stored Product Protection, 27 June to 2 July 2010, Estoril, Portugal. Julius Kühn-Institut, Berlin, Germany, pp. 789-792.

Arthur, F.H., 2012. Aerosols and contact insecticides as alternatives to methyl bromide in flour mills, processing plants, and food warehouses. J. Pest Sci. 85, 323-329.

Arthur, F.H., Casada, M.E., 2010. Directional flow of summer aeration to manage insect pests in stored wheat. Appl. Eng. Agric. 26, 115-122.

Bell, C.H., Savvidou, N., 1999. The toxicity of vikane (sulfuryl floride) to age groups of eggs of the Mediterranean flour moth (Ephestia kuehniella). J. Stored Prod. Res.
35, 233-247.

Boina, D.R., Subramanyam, Bh, 2012. Insect management with aerosols in foodprocessing facilities. In: Perveen, F. (Ed.), Insecticides: Advances in Integrated Pest Management (Chapter 9). http://www.intechopen.com. accessed 04.04.14.

Fields, P.G., 1992. The control of stored product insects and mites with extreme temperatures. J. Stored Prod. Res. 28, 89-118.

Fields, P.G., White, N.D.G., 2002. Alternatives to methyl bromide treatments for stored-product and quarantine insects. Annu. Rev. Entomol. 47, 331-359.

Flinn, P.W., Hagstrum, D.W., Muir, W.E., 1997. Effects of time of aeration, bin size, and latitude on insect populations in stored wheat: a simulation study. J. Econ. Entomol. 90, 646-651.

Howe, R.W., 1965. A summary of estimates of optimal and minimal conditions for population increase of some stored products insects. J. Stored Prod. Res. 1 177-184.

Jian, F., Jayas, D.S., 2012. Temperature monitoring. In: Hagstrum, D.W., Phillips, T.W., Cuperus, G. (Eds.), Stored Product Protection. Kansas State University, Manhattan, KS., USA, pp. 271-282.

Jian, F., Jayas, D.S., White, N.D.G., 2009. Temperature fluctuations and moisture migration in wheat stored for 15 months in a metal silo in Canada. J. Stored Prod. Res. 45, 82-90.

Johnson, J.A., Valero, K.A., 2003. Use of commercial freezers to control cowpea weevil, Callosobruchus maculatus (Coleoptera: Bruchidae) in organic garbanzo beans. J. Econ. Entomol. 96, 1952-1957.

Mullen, M.A., Arbogast, R.T., 1979. Time-temperature relationships for various stored-product insect eggs and chilling times for various commodities. J. Econ. Entomol. 72, 476-478.

Nagel, R.H., Shepard, H.H., 1934. The lethal effect of low temperatures on the various stages of the confused flour beetle. J. Agric. Res. 48, 1009-1016.

Navarro, S., 2012. Advanced grain storage methods for quality preservation and insect control based on aerated or hermetic storage and IPM. J. Agric. Eng. 49, $13-20$.

Navarro, S., Noyes, R.T., Jayas, D.S., 2002. Stored grain ecosystem and heat and moisture transfer in grain bulks. In: Navarro, S., Noyes, R.T., Jayas, D.S. (Eds.) The Mechanics and Physics of Modern Grain Aeration Management. CRC Press, Boca Raton, FL, pp. 35-78.

Navarro, S., Noyes, R.T., Casada, M., Arthur, F.H., 2012. Grain aeration. In: Hagstrum, D.W., Phillips, T.W., Cuperus, G. (Eds.), Stored Product Protection. Kansas State University, Manhattan, KS., USA, pp. 121-134.

Rulon, R.A., Maier, D.E., Boehije, M.D., 1999. A post-harvest economic model to evaluate grain chilling as an IPM technology. J. Stored Prod. Res. 35, 369-383.

SAS Institute, 2000. SAS Release 8.01. SAS Institute, Cary, NC.

Subramanyam, Bh., Mahroof, R., Brijwani, M., 2011. Heat treatment of grain-processing facilities for insect management: a historical overview and recent advances. Stewart Postharvest Rev. 7, 1-11.

Worden, G.C., 1987. Freeze-outs for Insect Control. Bulletin 4903-4904. Association of Operative Millers, Minneapolis, MN. 